\title{
Maturity Models for Digitalization in Manufacturing - Applicability for SMEs
}

\author{
Stefan Wiesner ${ }^{1}$, Paolo Gaiardelli ${ }^{2}$, Nicola Gritti ${ }^{2}$, Gianluca Oberti ${ }^{2}$ \\ ${ }^{1}$ BIBA - Bremer Institut für Produktion und Logistik GmbH at the University of Bremen, \\ Hochschulring 20, 28359 Bremen, Germany \\ ${ }^{2}$ Università degli Studi di Bergamo, Dalmine BG 24044, Italy. www.unibg.it \\ wie@biba.uni-bremen. de
}

\begin{abstract}
Digitalization is a challenging topic for manufacturing SMEs. Besides improving their technological base, they have to keep the business offer attractive, e.g. by bundling their products with smart services. In addition to limited resources, often the necessary knowledge is missing to select the right technologies and develop attractive services based on their functionality. Due to the resulting high risks, SMEs neglect the chances of digitization and lose competitiveness. To start with, they need a maturity assessment model that can help them understand their level of readiness to implement aspects, such as Industry 4.0. In order to identify and fit such a model for SMEs, already existing assessment methods were analyzed according to a series of selected dimensions linked to SMEs features. The evaluation result illustrates requirements that have to be addressed by a new maturity model suitable for SMEs attempting digitalization.
\end{abstract}

Keywords: Industry 4.0, Smart Services, SMEs, Maturity Model.

\section{Introduction}

A firm's competitive position is determined by the ability to innovate its product portfolio and the time required to bring new products to the market. This increasing customer willingness to ask for new features and the rapid dynamization of the manufacturing environment are main drivers behind digitalization. As a consequence, Industry 4.0 has the aim to integrate sensors, machines, workpieces, and IT systems along the value chain beyond a single enterprise. These connected systems can interact with one another using standard Internet-based protocols and analyze data to predict failure, configure themselves, and adapt to changes [1].

Together with the technological advance, manufacturers are required to develop assets that can quickly adapt to new requirements from the customers through services. Unfortunately, there are many firms that consider themselves as a builder of things and that state their gross margin, revenues and other key performance indicators solely in term of "the product". When companies have begun to wrap value-adding services around their product, their competitive advantage is only temporary with regard to the technological development. The services have to be based on the new digital possibilities to become smart services [2]. They go beyond the kinds of upkeep and upgrades 
the firm may be bundling with the product, both in their value to customers and in their cost efficiency to the company.

In many European countries, small and medium-sized enterprises (SMEs) are the backbone of the manufacturing sector. For example, Italy has over four million enterprises in industry, services and construction with almost 11 million employees, and with an average size per firm of only 3.04 employees [3]. With more than $53 \%$ of value added and approximately $63 \%$ of employment, SMEs in Germany provide the majority of jobs and value added in the non-financial business economy, similar to the rest of the EU [3]. In order to remain competitive in this increasingly dynamic environment, SMEs have to provide adequate smart services, depending on the maturity of the company. This requires adopting the right technological options from the vast number of different alternatives summarized under digitalization. Although their dimensions foster creativity and the flexibility, problems in the development of smart services could arise because of the under-capitalization and the delay in identifying the best strategy for what concerns the technology choice [4]. Following the above challenges and issues, the aim of this paper is to analyze if existing maturity models are suitable for digitalizing SMEs and the possible drawbacks that have to be taken into account when developing a new improved maturity model for SMEs following Industry 4.0.

\section{$2 \quad$ Methodology and research design}

Although literature encourages companies to develop servitization strategies in a digitalization context, providing several methodologies and tools to assess the maturity level of smart services, it offers little guidance how SMEs have to cope with a smart servitization journey. In order to answer this question, a two stage research, aiming at the creation of a theoretical model that highlights the main characteristics of maturity models in Industry 4.0 for SMEs, was conducted. First of all, an extensive research on the most cited dimensions that characterise barriers and challenges in SMEs was carried out. At the same time a literature review using the search terms ("Industry 4.0" OR "Industrie 4.0") AND ("maturity model" OR "maturity assessment") in titles and abstracts was realised starting from interdisciplinary search engines as Scopus and Google Scholar. Matching the two analyses achieved the identification of the most appropriate maturity models for our research and the creation of an initial conceptual model able to explain the different attributes of maturity models supporting smart servitization of SMEs. Having created this initial model, we presented it to a panel of academic and industrial experts to validate its consistency with SMEs characteristics. The crosscheck was carried out separately and the obtained feedback compared and unitedly agreed among the experts and researchers, in order to construct the final version of the model which is presented later in this paper.

\section{State of the Art Analysis}

The use of new digital technologies and the acquisition of knowledge will inevitably lead to new types of work and ways of working. This will necessitate changes to the 
structures within companies and the relationships between companies and will revolve around networks of manufacturing resources that are autonomous, capable of controlling themselves in response to different situations, self-configuring, knowledge-based, sensor equipped and spatially dispersed [5]. As a key component of this vision, smart factories will be embedded into inter-company value networks and will be characterized by end-to-end engineering. The goal of this integration is to deliver an end-to-end solution [6]. Industry 4.0 capabilities help to incorporate individual customer and product specific features into the design, configuration, ordering, planning, production, operation and recycling phases, dramatically reducing the time between an event occurring and the implementation of an appropriate response [5].

\subsection{Challenges for manufacturing SMEs in Digitalization}

While SMEs are often not led by a professional manager, they usually have a great capacity for improvisation [10]. Therefore, SMEs have a high potential for digitalization but they're also exposed to failure risk and greater financial constraints compared to the big companies [11]. The result is often a focus on sectors with medium (or medium-low) technology level, where the competitiveness is mainly based on price. While every fourth German manufacturing company already uses Industry 4.0 applications, from sensors to big-data to industrial 3D printing, the shift of business models from analogue to digital is an enormous challenge for SMEs. The companies must be open to new partnerships, as no vendor controls the whole process from sensor to invoice [7, 8]. Therefore, a fundamental criterion for a suitable maturity model is its general adaptability to SMEs organizational structure. It should support an agile company, enabling rapid decision-making and adaptation processes throughout every part of the business and across all business process areas [5].

According to a study among 420 German SMEs, the majority of the companies see a great potential in digitalization and invests between two and five percent of their sales. But there are still numerous challenges, which must be overcome. Many participants cite security, data protection, and loss of control over their own data, costs, time, or the high implementation effort as reasons for slowing things down. Examples of concrete implementations are still missing. Many digitization efforts would still fail because of the employees, who sometimes have little motivation or are not open to new ideas. Complex, incomprehensible technology and standstill after first developments are mentioned as well [9]. Thus, a suitable maturity model should not to be too complicated to be understood (simplicity), explaining the overall idea of digitalization and its related concepts, clarifying uncertainties instead of creating new ones. This includes implementation easiness as well.

The specific needs of SMEs, initially include information on the possibilities of digitalization, and subsequently providing guidance through the first steps of the transformation. They experience problems to identify concrete fields of action, programs and projects [12].The benefits of Smart Manufacturing have to be shown by success stories how it can be applied in SMEs. Required resources include motivation, training, road mapping and support on the actual implementation. Rather than fascination for technology, it needs to be assured that solutions yield the profits they are supposed to [11]. 
Consequently, an important function of a maturity model is the guidance provided for SMEs on how to attain a higher level of maturity in their specific domain and to continue in the right direction with their business strategy. It should allow them to position their business against external trends and give a guideline to select suitable technological and smart service options.

Strongly linked to the uncertainty about digitalization concepts, the knowledge requirements to use a maturity model is crucial for its suitability for SMEs. A high initial knowledge constitutes a sort of entry barrier. This has been confirmed in semi-structured interviews with practitioners and researchers. Companies perceive the concepts of Industry 4.0 as highly complex with no strategic guidance offered and lack a clear idea of Industry 4.0 resulting in uncertainty regarding benefits and outcomes [12].

\subsection{Model for Maturity Assessment and Technology Selection}

One of the first obstacles encountered by companies approaching digitalization is to understand their level of maturity, generally defined as "state of being complete, perfect or ready" [13] for this transformation. The objective of maturity assessment models is to provide means for assessing a company's current maturity to implement aspects of Industry 4.0 and identifying concrete measures to help them achieve a higher maturity stage in order to maximize the benefits [5].

In the literature it is possible to find several models with this aim but, in order to streamline the process, it has been decided to focus the attention on four models that are currently adopted (according to a survey among manufacturing SMEs in the territory) in the countries where the researchers come from: Italy and Germany. The choice of these models simplifies, in addition, their analysis as, in the past, the authors of this paper were involved in the creation of one of them.

Furthermore, the Italian economy is based on SMEs, as the $99.9 \%$ of Italian firms belongs to this category [16], which means that this target is surely relevant. This fact will not exclude, with any doubt, a broader discussion in the future thanks to the inclusion of additional models.

1. Schumacher et al. (2016): "Maturity model for assessing Industry 4.0 readiness and maturity of manufacturing enterprises" [12]

The model includes three distinct phases: an initial phase to create complete understanding of the domain of Industry 4.0, a core development phase to design and architect the model's structure as well as a practically applicable tool and an implementation phase to validate the resulting tool in real life application.

2. Jarrahi et al. (2017): "Smart service strategies in industry 4.0: a proposal of a readiness assessment methodology" [14]

This model is based upon the main drivers that characterize business and operational transformation in Industry 4.0 and smart service-based strategies. The methodology aims to assist companies through smart servitization in the Industry 4.0 scenario by adapting the most appropriate smart service strategies. 
3. Lichtblau (2015): "IMPULS - Industrie 4.0-Readiness" [15]

The model provided by IMPULS involves an online self-check tool that lets one calculate an Industry 4.0 scorecard. Companies can find out where they are already well prepared for Industry 4.0 and where they still have room for improvement. This readiness model is based on key principles like smart products and services.

4. Schuh et al. (2017): "Industrie 4.0 Maturity Index.

Managing the Digital Transformation of Companies" [5].

The maturity assessment model by Acatech takes as an input the current situation and the corporate strategy of the firm in order to provide a digital guidance roadmap as output, with a step-by-step approach to achieving the benefits that reduces the investment and implementation risks for the company.

\subsection{Applicability of existing Industry 4.0 Maturity Models for SMEs}

Table 1 below includes a brief evaluation of the four above-mentioned models according to the dimensions that we have identified as fundamental to perform an Industry 4.0 maturity assessment suitable for SMEs in section 3.1.

Table 1. Applicability evaluation of I4.0 maturity models for SMEs

\begin{tabular}{|c|c|c|c|c|}
\hline Method & Schumacher & Jarrahi & Lichtblau & Schuh \\
\hline $\begin{array}{c}\text { Simplicity \& } \\
\text { Implementation } \\
\text { easiness }\end{array}$ & & & 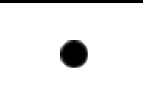 & (1) \\
\hline $\begin{array}{l}\text { Knowledge } \\
\text { requirements }\end{array}$ & () & (1) & (1) & $\boldsymbol{\theta}$ \\
\hline $\begin{array}{c}\text { Importance of } \\
\text { Organizational } \\
\text { Issues }\end{array}$ & $\Theta$ & () & () & \\
\hline Guidance provided & 0 & (1) & 0 & \\
\hline
\end{tabular}

The main advantage of Schumacher's model [12] is its transparency, which makes it quite simple to understand, thanks to its maturity assessment questionnaire and formula. Some background knowledge is very important at the earliest stage, as it's the basis for the establishment of evaluation weights. Its basic technical and implementation requirements are quite suitable for SMEs. The main reason behind the simplicity of Jarrahi's model [14] is the use of a questionnaire to classify the company in one of four levels. The model requires the user to have a medium knowledge level to better assess the maturity. A basic guidance is provided according to the level in which the company is classified. Lichtblau's model [15] requires very little time and resources involvement, being based on an online tool. It requires medium digitalization knowledge from the people that are going to fill the form to be consistent with the actual 
situation of the SME. Once again, there is a lack of guidance regarding the I4.0 framework. The completeness and broadness of Schuh's model [5] require quite heavy time and resource involvement. It doesn't require a special kind of initial knowledge. The inclusion of strategic objectives in the analysis make this model suitable for every company dimension, thanks also to the very detailed and tailored guidance provided according to the company's objectives.

\section{Requirements for a new SME Industry 4.0 Maturity Model}

Following the evaluation that we have performed, it is possible to identify important similarities among the four models. These common dimensions are crucial and they provide the starting point for identifying requirements to develop a new Industry 4.0 maturity model useful for SMEs.

The company's strategy and organizational structure is present in each model, they all agree that one important point to understand the maturity level of a company is looking at its strategy. The new model should take into account the long term strategy of the company and build a step by step development process, which can help SMEs to identify their specific strategic goal within the constraints. The guidance provision should be aligned with the pre-established strategic objective of the SME and consider also the addition of some intermediate milestones.

The digital transformation into a learning, agile company in Industry 4.0 requires a change in leadership and culture. Companies will be unable to achieve the desired agility if they simply introduce digital technologies without also addressing their corporate culture. Instead, they must begin by deciding how they want their company to do things in the future and which skills their employees will require. The new model should find a simple and clear way to assess employees' willingness to change work behavior. It shouldn't require employees to change their work behavior too rapid.

For digitalization companies have to determine how they can contribute to satisfying the end customer's needs. Even if the company doesn't itself deliver directly to the end customer, its product or service still forms part of the end customer's solution. The better the contributions made to this solution by the individual partners, the more successfully the companies in question will be able to differentiate themselves from the competition. The new model should find a clear and concise way to identify whether the company is focusing on the B2B or B2C customer needs. Therefore, the model should provide guidance for a periodical check of end user satisfaction.

In order to generate and analyze data and implement the corresponding decisions, the SMEs resources must acquire certain competencies or be upgraded with the relevant technological components. The new model should contain a straightforward method (weighted ranking) to assess the technological level of the company within the Industry 4.0 framework. Guidance should rationalize technology investments as the levels advance in order to avoid drastic expenses

Last but not least, the model shouldn't require a high level of knowledge to identify the SME in one of the strategic levels. In addition it should provide information about the benefits of each level. 


\section{Summary and Outlook}

This paper has presented an overview of the special challenges digitalization creates for SMEs. It has been illustrated that one of the major obstacles for these kind of companies is to assess their current situation regarding technology and smart service implementation, as well as to receive guidance on possible strategic development paths towards digitalization. Simplicity, the knowledge required, suitability for SME organization and the guidance provided have been identified as prerequisites for such methods. Four existing Industry 4.0 maturity models have been analyzed for their compliance towards these prerequisites. As no individual model could fully satisfy all prerequisites, requirements for a new SME maturity model have been derived.

After translating SMEs features into requirements and deciding which dimensions to include, in a next step the objective is to build a new SMEs-tailored maturity model. This model will specifically help SMEs to select the right technologies according to their maturity and provide guidance to develop value-adding smart services for their products. The first target of this model are Italian SMEs operating in the manufacturing sector, which often fail to grasp the overall concept of digitalization and all the opportunities coming with it, mainly because of the broadness of this topic. The model will be evaluated through application in several of these industrial cases.

\section{References}

1. Rüßmann, M., Lorenz, M., Gerbert, P., Waldner, M., Justus, J., Engel, P., Harnisch, M.: Industry 4.0: The Future of Productivity and Growth in Manufacturing (2015). Accessed 9 April 2018

2. Allmendinger, G., Lombreglia, R.: Four strategies for the age of smart services. Harvard Business Review 83(10), 131-4, 136, 138 passim (2005)

3. European Commission: SBA Fact Sheet 2016 (2016). Accessed 31 May 2018

4. Bottoncini, A., Pasetto, A., Rotondi, Z.: Sviluppo e prospettive dell'industria 4.0 in italia e ruolo strategico del credito. 51-66 Paginazione / Argomenti, $\mathrm{N}^{\circ} 4$ (2016): maggio - agosto (2016). doi: 10.14276/1971-8357.516

5. Schuh, G., Anderl, R., Gausemeier, J., Hompel, M. ten, Wahlster, W. (eds.): Industrie 4.0 Maturity Index. Managing the Digital Transformation of Companies. acatech STUDIE. Utz, Herbert, München (2017)

6. Kagermann, H., Helbig, J., Hellinger, A., Wahlster, W.: Umsetzungsempfehlungen für das Zukunftsprojekt Industrie 4.0. Deutschlands Zukunft als Produktionsstandort sichern ; Abschlussbericht des Arbeitskreises Industrie 4.0. Forschungsunion; Geschäftsstelle der Plattform Industrie 4.0, Berlin, Frankfurt/Main (2013)

7. Pütter, C.: Digitalisierung im Mittelstand: Probleme mit digitalen Geschäftsmodellen (2018)

8. Witsch, K., Kerkmann, C.: Industrie 4.0 light. Handelsblatt, 24 April 2018, 23

9. Adelmann, S.: Transformation mit Hindernissen (2017)

10. Wiesner, S., Nilsson, S., Thoben, K.-D.: Integrating Requirements Engineering for Different Domains in System Development - Lessons Learnt from Industrial SME Cases. Procedia CIRP 64, 351-356 (2017). doi: 10.1016/j.procir.2017.03.013 
11. Thoben, K.-D., Wiesner, S., Wuest, T.: "Industrie 4.0" and Smart Manufacturing - A Review of Research Issues and Application Examples. IJAT 11(1), 4-16 (2017). doi: 10.20965/ijat.2017.p0004

12. Schumacher, A., Erol, S., Sihn, W.: A Maturity Model for Assessing Industry 4.0 Readiness and Maturity of Manufacturing Enterprises. Procedia CIRP 52, 161-166 (2016). doi: 10.1016/j.procir.2016.07.040

13. Hanks, P., Pearsall, J., Stevenson, A.: Oxford dictionary of English. Oxford University Press, Oxford [etc.] (2010)

14. Jarrahi, F., Pezzotta, G., Cimini, C., Gaiardelli, P.: Smart service strategies in Industry 4.0. A proposal of a Readiness Assessment Methodology. In: The Spring Servitization Conference 2017 "Internationalisation through Servitization", pp. 232-240. Aston University (2017)

15. Lichtblau, K.: Industrie 4.0 - Readiness. Impuls-Stiftung (2015)

16. Rapporto Cerved PMI (2017) 